is documented, for example, for the last 130 kyr BP in Greenland ice cores. Instead, by using sediment cores from IODP (Integrated Ocean Drilling Program) and with CALYPSO and CASQ coring, the IMAGES community has recently delivered important contributions to the PAGES objective of investigating past land-ocean climate interactions at high temporal resolution. These studies addressed changes in paleotemperatures and -salinities in the western Pacific (e.g., Stott et al., 2004; Xu et al., 2006), the water vapor exchange between the equatorial eastern Pacific and western Atlantic (Leduc et al., 2007), and changes in monsoonal precipitation over West Africa (Weldeab et al., 2007). These promising results highlight the importance for IMAGES to continue with its strong efforts to assure financial support for future CALYPSO and CASQ coring expeditions and sediment core investigations in the tropical realm.

To synthesize and discuss the paleorecords now available on past variability of the hydrological cycle and associated land-ocean climate linkages, an IMAGES-PAGES-NSF workshop will take place in Trins, Austria, 30 May to 2 June (www.images-pages. org/news_2006-2007.html\#trins2007). Together, with the IMAGES Scientific Committee meeting in Shanghai, China, 8-9 September, prior to the International Conference of Paleoceanography (ICP 9, http://icp9.iodp.cn/), the Trins workshop will be dedicated to the identification of new coring sites and strategies to further investigate past changes in the hydrological cycle and to proceed with this theme relevant to PAGES objectives. In the longer term, the task of unraveling past changes in the hydrological cycle and in ocean- land linkages offer ample opportunities, and raise urgent needs, to converge and integrate marine-based and land-based paleoresearch.

\section{References}

Leduc, G., Vidal, L., Tachikawa, K., Rostek, F., Sonzogni, C., Beaufort, L. and Bard, E., 2007: Moisture transport across Central America as a positive feedback on abrupt climatic changes, Nature, 445 908-911.

Stott, L., Cannariato, K., Thunell, R., Haug, G., Koutavas, A. and Lund, S. 2004: Decline of surface temperature and salinity in the western tropical Pacific Ocean in the Holocene epoch, Nature, $\mathbf{4 3 1}$ 56-59.

Weijers, J.W.H., Schefuß, E., Schouten, S. and Sinninghe Damsté, J. 2007: Coupled thermal and hydrological Evolution of Tropical Africa over the last deglaciation, Science, 315: 1701-1704.

Weldeab, S., Schneider, R.R. and Koelling, M., 2006: Deglacial sea surface temperature and salinity increase in the western tropical Atlantic in synchrony with high latitude climate instabilities, Earth and Planetery Science Letters, 241: 699-706.

Xu, J., Kuhnt, W., Holbourn, A., Andersen, N. and Bartoli, G., 2006 Changes in the vertical profile of the Indonesian Throughflow during Termination Il: Evidence from the Timor Sea, Paleoceanography, 21: PA4202, doi: 10.1029/2006PA001278.

\title{
RESOLuTION - Rapid climatic and environmental shifts during Oxygen Isotope Stages 2 and 3 - linking high- resolution terrestrial, ice core and marine archives
}

\author{
Barbara Wohlfarth ${ }^{1}$, K. Helmens', S. Wastegård ${ }^{1}$, S. Bohncke², H. Renssen ${ }^{2}$, M. F. Sánchez-Goñil ${ }^{3}$, F. d'Errico ${ }^{3}$, T. Rasmussen ${ }^{4}$, S. Johnsen ${ }^{5}$ and \\ C. SPÖTL ${ }^{6}$ \\ 'Stockholm University, Sweden; Barbara@geo.su.se; ${ }^{2}$ Free University Amsterdam, The Netherlands; ${ }^{3} \mathrm{CNRS}$ and University of Bordeaux, France; \\ ${ }^{4}$ University of Tromsø, Norway; ${ }^{5}$ University of Copenhagen, Denmark; ${ }^{6}$ Innsbruck University, Austria
}

Understanding the complex paleoenvironmental processes associated with the rapid centennial- to millennial-scale Dansgaard-Oeschger (DO) oscillations and Heinrich $(\mathrm{H})$ events during the last glacial period is a major issue in paleoclimate research. These dramatic changes have been documented in ice-core, marine and terrestrial records, but large dating uncertainties prevent detailed, time-synchronous correlations between land, ocean and ice core archives. These correlations are necessary if the roles played by the different parts of Earth's environmental system are to be understood. The ESF EuroCores Project on EuroClimate RESOLuTION is addressing these issues by linking high-resolution, multi-proxy marine, terrestrial and ice-core records through detailed geochronology and time-synchronous tephra horizons (Fig. 1). Moreover, it explores the impact of abrupt climatic changes on Paleolithic populations in Europe and performs transient simulations with a coupled atmosphere-oceanvegetation model to simulate realistic DO stadial-interstadial changes. The overall aim of RESOLUTION is to propose a scenario that can explain the different timing and impact of DO climate variability on the Atlantic Ocean and adjacent European regions, thus significantly contributing to the debate on mechanisms underlying sub-orbital climate variability.

RESOLUTION is organized around different work packages, each addressing different parts of the climate system. Terrestrial records comprise lacustrine sequences from northern Finland, eastern Germany and eastern France, and marine sequences stretch from the high-latitude to the mid-latitude North Atlantic. The marine records have the advantage that they contain both terrestrial (pollen, microcharcoal) and marine climatic tracers and thus provide a direct correlation between terrestrial (vegetation, fire) and marine environmental responses in western Europe to $\mathrm{DO}$ and $\mathrm{H}$ events.

For each of our sites we establish detailed, qualitative and quantitative records of biological and geochemical proxies and combine these with analyses of timesynchronous marker horizons (e.g., crypto-tephra, paleointensity changes) and carefully established chronologies. This concerted approach allows the impact of DO oscillations and $\mathrm{H}$ events on the terrestrial paleoenvironment to be deciphered and enables detailed comparisons on leads/lags between ice-core, marine and terrestrial records. It also elucidates to what extent these abrupt changes influenced settlement patterns and subsidence strategies of late Neanderthal and Upper Paleolithic populations.

During the two workshops in Les Eyzies, France (September, 2005) and Svinaberga, Sweden (October, 2006) RESOLUTION group members decided to zoom in with highest possible temporal resolution on the time windows of Greenland Interstadials (GIS) 3-8, 14-16 and H event 4. Key tephra layers during this interval are Z2 and the Fugloyarbanki Teph$\mathrm{ra}$, although several more crypto tephras are currently under investigation in the Greenland ice cores and in the marine and terrestrial sequences of our transect. Together with the Laschamp and Mono Lake geomagnetic events, these tephra layers form important correlation tools between terrestrial, marine and ice core records. Precise correlations, however, not only depend on specific marker horizons, but also on the choice of a common chronological approach. RESOLUTION uses for compari- 


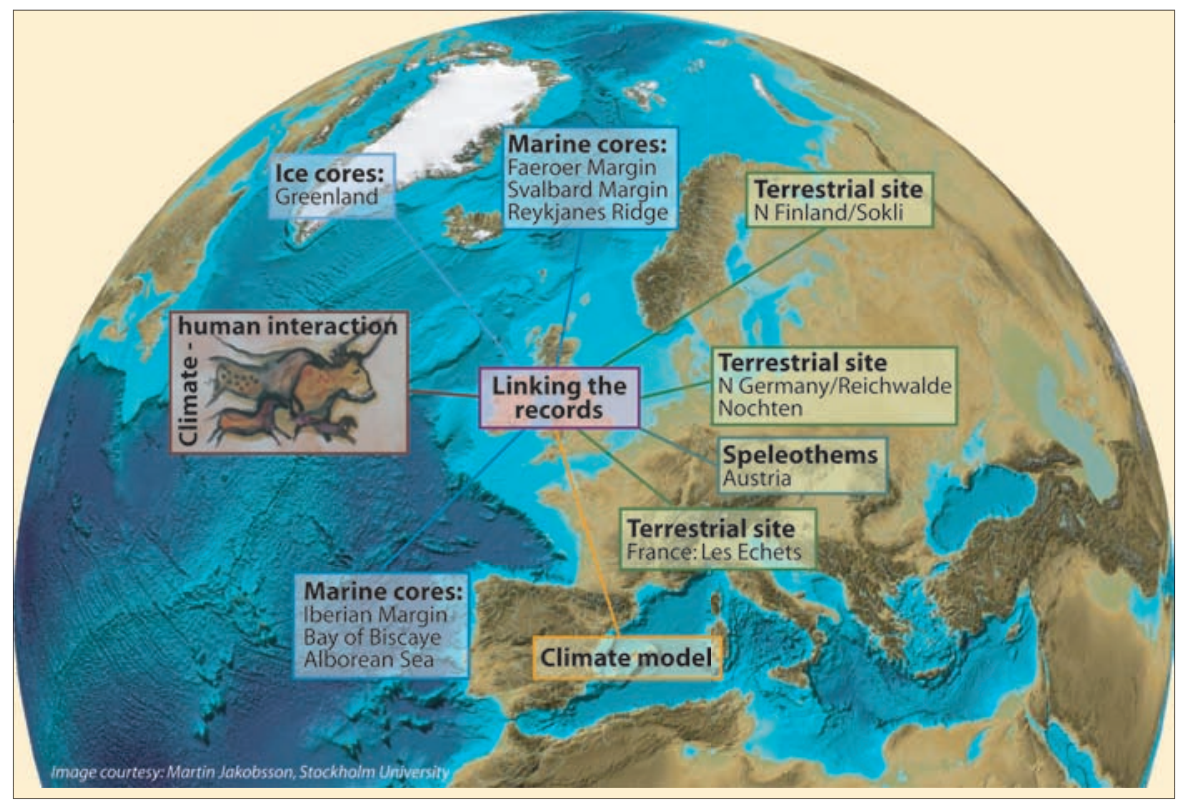

Figure 1: The different sites of the RESOLUTION network project.

sons the GICC05 chronology back to $42 \mathrm{kyr}$ BP (Andersen et al., 2006) and the GRIPss09 chronology back to $60 \mathrm{kyr}$ BP (Johnsen et al., 2001). All ${ }^{14} \mathrm{C}$ dated sequences are wiggle-matched against the comparison curve of Hughen et al. (2006), until the new IntCal calibration curve is released.
Transient simulations with a coupled atwill finally be compared with the data sets emerging from the land and ocean sites.

RESOLUTION started in January 2005 and will end in December 2008. Financial support for the project is provided by research councils in Sweden, Denmark, The Netherlands and France and has enabled the recruitment of PhD students and postdoctoral researchers. The next workshop (1-4 October, 2007) will be organized in The Netherlands. Please contact Barbara Wohlfarth (Barbara@geo.su.se) for enquiries about RESOLUTION and Hans Renssen (hans.renssen@geo.falw.vu.nl) regarding the upcoming workshop.

\section{References}

Andersen, K.K., Svensson, A., Johnsen, S.J., Rasmussen, S.O., Bigler, M., Röthlisberger, R., Ruth, U., Siggaard-Andersen, M-L., Steffensen, J.P., Dahl-Jensen, D., Vinther, B.M., and Clausen, H.B., 2006: The Greenland Ice Core Chronology 2005, 15-42 ka. Part 1: constructing the time scale, Quaternary Science Reviews, 25: 3246-3257.

Hughen, K.A., Southon, J.A., Lehman, S.J., Bertrand, C.J.H., and Turnbull, J., 2006: Marine-derived ${ }^{14} \mathrm{C}$ calibration and activity record for the past 50,000 years updated from the Cariaco Basin, Quaternary Science Reviews, 25: 3216-3227.

Johnsen, S.J., Dahl-Jensen, D., Gundestrup, N., Steffensen, J.P., Clausen, H.B., Miller, H., Masson-Delmotte, V., Sveinbjörnsdottir, A.E., and White, J., 2001: Oxygen isotope and palaeotemperature records from six Greenland ice-core stations: Camp Century, Dye-3, GRIP, GISP2, Renland and NorthGRIP, Journal of Quaternary Sciences, 16: 299-307.

\section{Past Human-Climate-Ecosystem Interactions (PHAROS)}

John Dearing ${ }^{1}$ and Rick Battarbee ${ }^{2}$

'Department of Geography, University of Liverpool, UK.; j.dearing@liverpool.ac.uk Environmental Change Research Centre, University College London, UK; ufcabat@ucl.ac.uk

\section{Introduction}

The Focus 4 PHAROS theme addresses interactions between climate, ecological processes, and human activities in the past in order to understand better the behavior of ecological systems in the present and future (Oldfield and Dearing, 2003; Dearing et al., 2006a,b). It seeks to address three key gaps in scientific knowledge. First, complex relationships between climate, environment and human activities lie at the heart of modern ecological concerns, yet the longer-term context for these relationships are often poorly understood (cf. Dearing, 2006). These include: the role of spatial scale in determining the nature of interactions; the impacts of multiple stressors on ecosystems through time; and the direct effects of human activities on the earth/climate system as opposed to the cumulative indirect effects of local impacts. Second, the response of ecosystems and associated ecological processes to rapid rates of climate change, with and

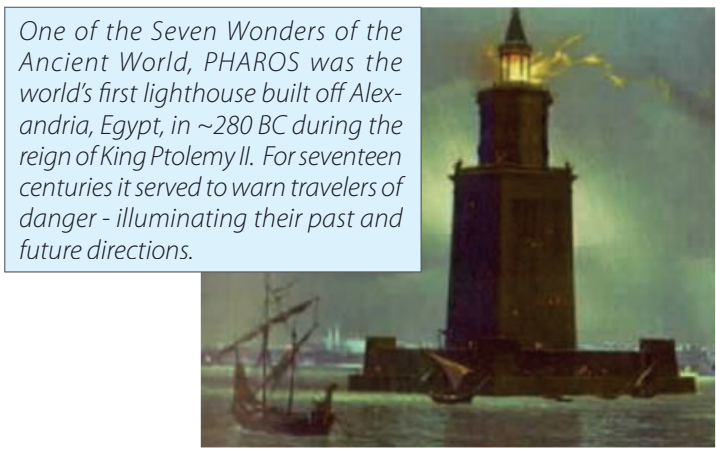

without changing human activities, requires urgent attention. This is particularly the case for ecosystems that are known to be highly sensitive to climate change (IPCC 2001; 2007 forthcoming), or where model projections indicate regions of very rapid climate change in future (e.g., Giorgi, 2006; Williams et al., 2007). Third, the past and current status of key ecological resources and processes is incomplete for many regions. There are no comprehensive reviews of changing hydrology and hydrobiology, soil and land-cover, or disturbance regimes over decadal-to-millennial time scales. This information is vital in assessing the current status of ecosystem services, developing sustainable management strategies, and for testing the current generation of climate and carbon models, Dynamic Global Vegetation Models (DVGM's), and impactassessment models (Prentice et al., 1992; Sellers et al., 1997; Battarbee et al., 2005; Anderson et al., 2006). An important ele- ment in PHAROS is a new working group, INTEMODS, tasked with promoting integration between case-studies, producing regional/global syntheses and developing modeling tools.

\section{Theme Goals}

PHAROS seeks to understand ecosystem change on different time scales and at spatial scales ranging from local to global. For any specified ecosystem the following generic questions are posed:

- What is the nature of human activities that have influenced and are influencing modern ecological systems? For example, what are the historic links between irrigation and flood regime under different environmental conditions?

- How have these human activities interacted with climate processes through feedbacks? For example, at what spatial 